\title{
ORDEN GLOBAL JUSTO Y DERECHO INTERNACIONAL EN TRANSFORMACIÓN
}

\author{
Cristina García Pascual \\ Universidad de Valencia
}

I.

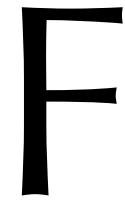

rancisco LAPORTA y Liborio HierRo constituyen dos referentes para los estudiosos de la filosofía del derecho de mi generación. Un ejemplo de rigor científico y dedicación al estudio en una Universidad que en unos tiempos pudo ser mejor pero tal vez también, en otros, de mayor incertidumbre y precariedad que la actual. Para quienes seguimos atentos a sus publicaciones resultan especialmente interesantes algunos de sus últimos escritos en los que ambos autores dirigen la mirada hacia el orden jurídico internacional, hacia el fenómeno de la globalización y las tensiones que esta plantea al jurista. ¿Qué podrá decir quien reivindica el gobierno de las leyes generales y abstractas de la norma internacional?, ¿qué valoración le podrá merecer la incesante producción de normas en ese espacio donde no existe ni representación, ni instituciones que impongan sanciones centralizadas, allí donde la fragmentación de los ordenes normativos es la regla? O ¿cómo podrá responder un jurista positivista preocupado por los problemas de la igualdad y por la protección de los derechos sociales a la pregunta acerca de un posible derecho a un mundo justo?

Medir la propias ideas pensadas para el espacio estatal trasladándolas al contexto supraestatal fue lo que hizo hace muchas décadas Hans KELSEN en lo que podríamos denominar la construcción de una «teoría pura del derecho internacional» y también Herbert HART en el capítulo décimo de El concepto de derecho donde sostuvo que el entramado de costumbres, reglas o principios que se conocen bajo el nombre de derecho internacional no tienen carácter jurídico. Hoy tal vez ese ejercicio parezca más necesario todavía, porque nunca como hoy sentimos las limitaciones de las soberanías estatales, el avance del pluralismo jurídico, la fuerza expansiva del capitalismo y la necesidad, y a la vez la dificultad de aprehender o reducir a conceptos y categorías claras las estructuras y pautas de funcionamiento de la globalización.

En esta difícil empresa se embarca Francisco LAPORTA en dos excelentes trabajos, uno sobre «El imperio de la ley y la globalización» que constituye el capítulo once de su hermoso libro El Imperio de la ley y el otro sobre «Gobernanza y softlaw» que aparece en la obra colectiva Entre Estado y Cosmopolis, donde también Liborio HIERRO se enfrenta el problema de la justicia más allá de las fronteras estatales con un texto titulado «Justicia global y justicia legal. ¿'Tenemos derecho a un mundo justo?». Y digo 
difícil empresa porque cuando el iusfilósofo se traslada con sus herramientas al escenario de la globalización el abanico de problemas básicos de la filosofía del derecho se plantea con una intensidad inusitada como si fueran acuciantes aporías que deben resolverse si pretendemos entender mínimamente el mundo en que vivimos. Estoy pensando en cuestiones tan básicas para el jurista como qué es el derecho o la ley, su identificación o reconocimiento, por ejemplo, a la hora de valorar el fenómeno del softlaw o cómo nacen y evolucionan los ordenes jurídicos frente a la crisis de la soberanía del Estado y la expansión del pluralismo jurídico, o más aún dónde queda en el mundo de la gobernanza la relación del derecho con el poder y la fuerza o el problema de la obediencia a las normas.

De alguna manera pensar en el lugar del derecho en el ámbito internacional o supranacional significa tanto como pensar en el orden del mundo, eso que en otro lugar he querido denominar la norma mundi, es decir, las posibilidades del derecho para gobernar a la humanidad, para establecer pautas de justicia universales o como mínimo para diseñar vías para la extensión del principio de legalidad más allá de las fronteras estatales. Estas tareas difícilmente se pueden emprender con éxito y solo pensarlas parece que nos desplazan del derecho a la utopía, allí donde imaginamos un mundo en el que sea posible vencer la pobreza, la guerra o la amenaza de desastres medioambientales o tal vez nos lleva al más crudo escepticismo cuando consideramos muerto o superado el derecho internacional por un entramado de relaciones económicas con capacidad de autogobernarse fuera de los cauces de ese derecho envejecido y derribado por los imperativos de la nueva realidad. El jurista se encontraría así atrapado en el conocido dilema que describe Martti KosKENNIEMI: entre ser una apologeta del poder, de lo real, si no consigue ir mas allá de la descripción de los intereses en juego, o caer en la utopía y tal vez ser irrelevante, si por alejado de esos mismos intereses en juego no nos ofrece más que una ética. Atrapado entonces entre mantener el discurso descriptivo de quien se limita a dar cuenta del complejo del entramado de relaciones de poder a escala mundial o mantener un discurso prescriptivo, carente de relación con la realidad, entre la apología de lo real y la utopía de lo imposible. Mantenerse alejado de ambos peligros navegando en el estrecho margen de agua brava que transcurre entre Scila y Caribdi es extremadamente difícil, imposible atendiendo a KOSKENNIEMI, pero ese es, sin embargo, el lugar del jurista que piensa el derecho fuera de las fronteras de Estado y es el lugar donde cabe situar las reflexiones de los profesores Francisco LAPORTA y Liborio HIERRO. Aprovecharé esta imagen para realizar algunos apuntes críticos a los planteamientos de ambos autores en lo que podría ser una vindicación del derecho internacional.

\section{II.}

Francisco LAPORTA se declara escéptico sobre las posibilidades del derecho global para una suficiente realización del ideal del imperio de la ley. ¿Y cómo no ser escépticos si ya en el ámbito estatal debemos dejar constancia de la crisis de la legalidad? Pero el escepticismo de LAPORTA resulta todavía más profundo que el que podría expresar cualquier jurista ante las posibilidades del derecho de revertir o someter a reglas los procesos de globalización porque en su análisis el derecho internacional público parece un orden normativo en cierta medida superado e insuficiente ante la nueva realidad 
de un «derecho global» o «transfronterizo» que poco o nada tiene que ver con el derecho internacional en su versión westfaliana o incluso en su versión kelseniana. Nos dice nuestro autor que la globalización «en su dimensión jurídica, aspira a ir mas allá de las coordenadas que definen el derecho internacional». O que el derecho global pretende «ser algo más que un derecho internacional desarrollado» ${ }^{1}$. De manera que la nueva lex mercatoria, la OMC con sus principios, reglas o decisiones o el llamado soft law no serían variaciones sobre los mismos elementos (vieja lex mercatoria, tratados o normas programáticas), sino nuevas realidades y parte de un derecho diferente. Y más aún ese nuevo derecho, esa nueva realidad pondrían «en cuestión las herramientas teóricas y conceptuales que habían tratado de dar cuenta de la realidad del Derecho y del Estado concebidos desde el prisma territorial» ${ }^{2}$.

Pero pretender deslindar de manera clara esa nueva categoría de un derecho global o transfronterizo diferente y separado del derecho internacional, o pensar que es posible entender la globalización sin las directrices del derecho internacional público me parece errado y peligrosamente cercano a una larga tradición de negación del derecho internacional que se remontan a tiempos muy anteriores al fenómeno de la globalización tal y como lo conocemos hoy en día.

LAPORTA se pregunta «si al lado del Derecho interno o doméstico y del derecho internacional, cabe pensar un Derecho transfronterizo, es decir, un modo característico y nuevo de regular esas interacciones actuales cuando no se da la existencia de gobiernos competentes, ni la vigencia global de normas jurídicas adecuadas, ni la posibilidad, ni siquiera remota, de acudir al respaldo coactivo para garantizar el cumplimiento de norma alguna» ${ }^{3}$. Pero la inexistencia de gobiernos competentes o la inexistencia de normas globales coactivas son los males que para muchos analistas aquejan al derecho internacional casi desde su nacimiento. De manera que no parece claro, en esa distinción entre derecho internacional y derecho global o transfronterizo, si se entiende que el derecho internacional ha superado ya esos males endémicos y ahora es un orden perfectamente formalizado pero reducido al campo de aplicación muy limitado de las relaciones interestatales (parecería que el sistema westfaliano sigue vivo) o justamente por no haberlos superado es un orden inoperante para hacer frente a las nuevas realidades de las que debería ocuparse el derecho global cuyas debilidades sin embargo parecen idénticas a las del derecho internacional.

$\mathrm{Y}$ justamente porque en el espacio internacional no existe un poder soberano capaz de imponer las normas por la fuerza algunos pensadores han sostenido a lo largo de la historia que el ideal del imperio de la ley o el principio de legalidad era ajeno al derecho internacional, es decir estaríamos ante un ideal que no puede extenderse más allá de las fronteras del Estado. En el espacio exterior la única posición admisible parecería la de realista o tal vez la del apologeta del poder, que abandona la especulación filosófica y nos traslada la constante imposición de la fuerza por encima de cualquier regla jurídica o moral.

${ }^{1}$ F. J. LAPORTA, El imperio de la ley. Una visión actual, Madrid, Trotta, 2007, 255.

2 F. J. LAPORTA, «Gobernanza y soflaw: nuevos perfiles jurídicos de la sociedad internacional», en A. Ruiz Miguel (ed.), Entre Estado y cosmopolis. Derecho y justicia en un mundo global, Madrid, Trotta, 2007, 42.

3 Ibid., 41. 
Es verdad que para algunos representantes de esa tradición crítica o negadora del derecho internacional, como podrían ser SCHMITT o POSNER, el rule of law tampoco es un principio especialmente valioso en sí mismo ni siquiera en el ámbito estatal. Y que no cabe duda que esta no puede ser la posición de Francisco LAPORTA, antes al contrario podemos razonablemente pensar que su vindicación del imperio de la ley como condición necesaria del valor de la autonomía personal no puede quedar circunscrita al Estado, porque también fuera del Estado parece legítimo aspirar a la autonomía personal. Pues bien creo que la defensa del imperio de la ley fuera de las fronteras del Estado está unida conceptualmente a la defensa del derecho internacional así lo entendió el gran KELSEN, así lo entienden destacados internacionalistas en la actualidad.

En el año 2002 la Comisión de Derecho Internacional de la ONU nombró un grupo de estudio presidido por el propio KosKENNIEMI sobre la fragmentación del derecho internacional, su diversificación y expansión. Se podría decir que en el nombramiento de un grupo de estudio a tal fin se esconde ese sentimiento de profunda desazón del jurista, que también se expresa en los textos de LAPORTA, ante la posibilidad de que la globalización haga inoperantes las categorías jurídicas que nos sirven para entender y actuar en nuestro mundo. En el informe final, sin embargo, no se separa el derecho internacional del llamado derecho global sino que se describe una única realidad, la del derecho internacional, fuertemente fragmentada, eso sí, en distintos regímenes ${ }^{4}$ y se intenta responder a las preguntas que esta situación de fragmentación plantea: «¿Cuál es la naturaleza de los sistemas normativos especializadas? ¿Cómo se deben concebir las relaciones inter se? ¿Qué normas deben gobernar sus conflictos?» $\gg^{5}$. La respuesta a estas cuestiones se realiza desde una visión formalista del trabajo del jurista que tiene algunos puntos de unión con el formalismo de LAPORTA pero que desemboca en una clara defensa del derecho internacional como el único espacio sobre el que proyectar los ideales del gobierno de las leyes. Dice el informe:

El esfuerzo mismo para sondear una técnica jurídica profesional coherente en un mundo fragmentado expresa la convicción de que los conflictos entre los regímenes especializados pueden ser superados por la ley [...] Siempre ha habido Estados que han considerado el derecho internacional incompatible con su soberanía. Del mismo modo, pueden existir hoy regímenes que consideren el derecho internacional una intrusión ajena. Hay pocas razones para ceder a la lógica de «aislamiento clínico» [...] Si se necesita el derecho internacional como una estructura de coordinación y cooperación entre Estados (soberanos), no menos se necesita con el fin de coordinar y organizar la cooperación de complejos de reglas y instituciones (autónomas) ${ }^{6}$.

La práctica del derecho le exige al jurista una búsqueda de reglas comunes con las que resolver los conflictos, tanto entre Estados, entre órdenes de normas, como entre entramados de interacciones, y ciertamente no parece compatible el jus congens y la jerarquía de fuentes que implica con una perspectiva horizontal de todas esas realidades. Tampoco parece compatible trabajar con las normas jurídicas, situarnos en el punto

${ }^{4}$ M. Koskenniemi, Report of the Study Group of the International Law Commission, «Fragmentation of International Law: Difficulties Arising from the Diversification and Expansion of International Law», A/ CN.4/L.682, 13 de abril de 2006, párr. 482.

5 Ibid., A/CN.4/L.682, párr. 483.

${ }^{6}$ Ibid., A/CN.4/L.682, párr. 487. 
de vista interno y pensar en clave de pluralismo jurídico, a no ser que entendamos este como reconducible en última instancia a un cierto monismo.

De manera que si defendemos el ideal del gobierno de las leyes generales y abstractas en el ámbito del Estado o incluso en el de las relaciones entre los Estados creo que deberíamos también defenderlo en el mundo globalizado y no parece que esto se pueda proyectar fuera de los márgenes del derecho internacional cuya naturaleza y características, sin duda, plantea grandes problemas al estudioso y todos ellos, y en esto coincido con LAPORTA, problemas filosóficos.

\section{III.}

También creo debemos partir de la estructura normativa que nos ofrece el derecho internacional para enfrentar la pregunta que Liborio HIERRO nos propone acerca de la posible existencia de un derecho a un mundo justo. En la respuesta deberemos evitar la formulación de utopías que se muestren incapaces de incidir en la realidad. Para el profesor HIERRO los problemas de justicia internacional serían la guerra, el hambre y la degradación del medio ambiente ${ }^{7}$ y difícilmente de esos tres males podemos liberarnos sin abrazarnos, siguiendo a KELSEN, al ideal del lento y constante perfeccionamiento del derecho internacional. Nos proyectamos hacia un futuro mejor pero no desde el vacío normativo puesto que ya el Derecho internacional de nuestros días y sus grandes instituciones pueden entenderse como un diseño para disuadir la violencia, evitar la guerra y castigar las violaciones masivas de derechos humanos.

La filosofía política y moral actual se ocupa desde hace muchas décadas de los problemas de la justicia internacional y el profesor HIERRO da cuenta de algunas de las más interesantes posiciones que se enfrentan en el debate sobre la posibilidad de desarrollar o extender los criterios de justicia pensados para comunidades concretas al ámbito supranacional de la comunidad mundial. En este marco, como es sabido, las propuestas son variadas y extremadamente difíciles de implementar en la realidad y deben enfrentarse a todas aquellas teorías que directamente niegan la existencia políticojurídica de una comunidad más allá de la propia familia, pueblo, nación o Estado. Se discute en torno a la justificación de la preferencia para los con-nacionales o, por ejemplo, se buscan razones que sostengan una obligación de ayudar a terceros en países y culturas lejanas a la nuestra. Para SINGER, y desde el utilitarismo, el problema del hambre «utilitaristamente» nos interesa a todos y a todos nos «conviene» resolverlo. ¿Es posible, se pregunta el pensador australiano, hacer algo que nos cause un sufrimiento inferior al sufrimiento de la inacción? POGGE, por su parte, se muestra comprometido con el desarrollo de la justicia como equidad en el ámbito global ya antes incluso de que el propio Jonh RAWLS negara la posibilidad de trasladar su teoría fuera del ámbito de la comunidad estatal. Se desarrollan así argumentos que legitiman la deberes frente a las personas ajenas, a mi propia familia o a mi comunidad política y se debaten criterios para resolver los enormes desequilibrios socio-económicos del planeta.

7 L. HIERRO, «Justicia global y justicia legal. ¿'Tenemos derecho a un mundo justo?», en A. RuIZ MiguEL (ed.), Entre Estado y cosmopolis. Derecho y justicia en un mundo global, Madrid, Trotta, 2007, 83 y ss. 
Todo este ingente debate que ocupa gran parte de la discusión filosófico-política actual me parece que pone en cuestión presupuestos teóricos que en gran parte ya están implícitos en el desarrollo de algunas normativas internacionales o de algunas instituciones jurídicas que desde la Segunda Guerra Mundial se han desarrollado al amparo de la ONU. La discusión sobre la justicia cosmopolita da la impresión que camina un paso por detrás del debate estrictamente jurídico, discutiendo argumentos que fuera de discusión sirven a los juristas para perfilar nuevas estructuras de un orden jurídico internacional.

El derecho internacional de los derechos humanos, estrechamente vinculado al derecho internacional humanitario y al derecho penal internacional, dota de una base jurídica a la aspiración de una sociedad en paz, y cabe decir que tantas bolsas de pobreza y tantos desastres medioambientales están estrechamente relacionados, son causa y consecuencia, con los conflictos armados. Al amparo de tratados, convenciones o declaraciones de derechos hoy en día contamos con una red de tribunales internacionales que día a día resuelven controversias en materia de derechos humanos produciendo un bagaje jurisprudencial que tiene fuerza de precedente jurídico para muchos otros tribunales o, al menos, eso que podríamos denominar, fuerza simbólica. Cuando algunos filósofos morales se preguntan sobre la existencia de una comunidad mundial donde existan obligaciones para con los otros, parecen olvidar algo que la norma internacional ya implica o que los jueces internacionales ya asumen como un dato de hecho, puesto que si el proceso es internacional la comunidad moral que se afirma es la comunidad internacional. O citando a Hannah ARENDT, «la ley presupone precisamente que existe una comunidad en lo humano con aquellos a quienes acusamos, juzgamos y condenamos» ${ }^{8}$.

En cierta medida la comunidad internacional que algunos filósofos de la moral buscan y quieren justificar para sobre la misma construir un mundo más justo, ya existe para los juristas. Es la comunidad, todavía frágil por supuesto, que gobierna el derecho internacional.

${ }^{8}$ H. ARENDT, Eichmann en Jerusalén. Un estudio sobre la banalidad del mal, trad. de C. RIBALTA, Barcelona, Lumen, 1999, 364. 